\title{
Limited Utility for Benzodiazepines in Chronic Pain Management: A Narrative Review
}

\author{
Steven L. Wright
}

Received: March 4, 2020 / Published online: May 6, 2020

(C) The Author(s) 2020

\begin{abstract}
Introduction: Controversy and uncertainty exist about the use of benzodiazepine receptor agonists (BZRAs) in pain management. This article curates available research to determine the appropriate role of BZRAs in the course of pain management, and how prescribers might address these challenges.

Methods: A narrative review was performed to determine the appropriate role of BZRAs in pain management and to develop practice recommendations. Publications were identified by a search of PubMed, references of retrieved reports, guidelines, and the author's personal files.

Results: BZRAs were found to have analgesic benefit for two pain conditions: burning mouth syndrome and stiff person syndrome. Absence
\end{abstract}

Digital Features To view digital features for this article go to https://doi.org/10.6084/m9.figshare.12145251.

S. L. Wright $(\bowtie)$

Alliance for Benzodiazepine Best Practices, Littleton, CO, USA

e-mail: sleighwright@gmail.com of research, heterogeneity of trials, and small sample sizes precluded drawing conclusions about efficacy of BZRAs for the other 109 pain conditions explored. Data supports the use of BZRAs to treat co-occurring insomnia and anxiety disorders but only when alternatives are inadequate and only for short periods of time (2-4 weeks). The utility of BZRAs is limited by loss of efficacy that may be seen with continued use and adverse reactions including physiologic dependence which develops in $20-100 \%$ of those who take these agents for more than a month.

Conclusions: BZRAs are often used inappropriately in pain management. Their initiation and duration of use should be limited to a narrow range of conditions. When prescribed for 4 weeks or more, patients should be encouraged to discontinue them through a supported, slow tapering process that may take 12-18 months or longer.

Keywords: Benzodiazepine; Benzodiazepine receptor agonist; Chronic pain; Overdose; Pain management; Tapering; Withdrawal 
Key Summary Points

Benzodiazepine receptor agonists (BZRAs) are frequently prescribed in pain management

Benzodiazepines (BZs) may have an analgesic role in burning mouth syndrome and stiff person syndrome

BZRAs have a narrow role (2-4 weeks) in the management of co-occurring insomnia and anxiety disorders

BZRA deprescribing should be offered to all patients on these agents for more than a month and should proceed by slow tapering that may take a year or more

\section{INTRODUCTION}

Chronic pain is quite common, although published estimates vary widely. When "chronic" is not specifically defined, $40 \%$ of survey respondents in both developed and developing countries report having that condition [1]. When "persistent pain" is defined as pain present on all or most days in the preceding 3 months, it is reported by one out of five of adults in the USA, half of whom describe it as sometimes unbearable [2]. Decades ago, increased recognition of the importance of pain led to recommendations that inquiry about pain be regarded as the "fifth vital sign". Vital as it is, however, pain is not objective, and, in fact, this concept encouraged opioid overprescribing due to the underlying implied false syllogism that significant pain called for opioid analgesia. Widespread adoption of this simplistic heuristic set into motion a dynamic progression of harms, shaping today's opioid crisis.

Chronic pain management is quite complex and is not equivalent to opioid management. While analgesia lies on the path to success, improved function is the true north and achieving it is a far greater challenge. This includes the need to manage multiple current and limit future potential comorbidities, especially the highly prevalent psychological conditions. Technically, chronic pain is defined as that lasting more than 3-6 months. To affected individuals, however, this means an inability to heal which may result in adverse affective attribution or suffering. This, in turn, may compound existing or generate new medical challenges that need to be addressed if functional gains are to be attained.

Available for 60 years, benzodiazepine receptor agonists (BZRAs) have often been prescribed for such clinical conditions. These compounds work primarily by enhancing the effect of the non-protein amino acid $\gamma$ aminobutyric acid (GABA), the major inhibitory neurotransmitter of the central nervous system (CNS) [3], which is active at the orthosteric site on the $G_{A B A}$ receptor $\left(G A B A_{A} R\right)$. BZRAs, on the other hand, are GABAergic primarily as positive allosteric modulators at the benzodiazepine recognition site of $\mathrm{GABA}_{\mathrm{A}} \mathrm{R}$ to increase chloride conductance amplifying GABA inhibition [3, 4]. A diverse range of substances are $\mathrm{GABA}_{\mathrm{A}} \mathrm{R}$ agonists, including the barbiturates, carisoprodol, neurosteroids, alcohol, certain anesthetics such as propofol, as well as some compounds found in certain plants like valerian and cannabis [5-7]. The term BZRA, however, is primarily reserved for the benzodiazepines (BZs), defined chemically as the fusion of a benzine and diazepine ring, and the non-benzodiazepines or Z-drugs, so-called as the generic nomenclature of the individual medications includes the letter " $\mathrm{z}$ ".

To many prescribers BZRAs appear as ready solutions to help those struggling with anxiety and insomnia, and in the short term they are effective, although trouble may ensue later. In the US population, $6-13 \%$ receive a $\mathrm{BZ}$ prescription in any 1 year [8-11]. In pain management, BZRAs assume a more prominent role being prescribed to $10-33 \%$ of persons who are also receiving opioids [12-19]. Of particular concern, use is even greater among those at high risk: the elderly and those who have multiple prescribers, are on at least 200 morphine milligram equivalent (MME) daily opioid doses, 
or have greater mental health and substance use problems [14, 18-20].

Harm exposure is clearly increased by such respiratory-depressant polypharmacy. BZ-opioid combinations more than double the likelihood of emergency department and hospital admissions [17]. In addition, there has been a progressive increase in the proportion of opioidassociated accidental deaths in the USA in which BZs have been identified, rising from $13 \%$ in 1999 to $31 \%$ in 2013 [21]. That proportion is even greater in some locales: $52 \%$ in the 11 states reporting to the Centers for Disease Control and Prevention (CDC)'s Enhanced State Opioid Overdose Surveillance program [22] and $80 \%$ in North Carolina described in a separate study [23].

BZ involvement in opioid-related negative outcomes is a compelling reason to reconsider public health and clinical approaches. A significant contributing factor is that of inappropriate BZRA prescribing [24]. In response, the US Food and Drug Administration (FDA) requires a boxed warning about co-prescribing on about 400 opioid- and BZRA-containing products [25]. Careful examination of risks, benefits, and utility at the clinical level is now indicated as well. While BZRAs figure prominently in the treatment of anxiety and insomnia, BZs are also employed with analgesic intent, even though safety and efficacy are not well described. In this review, available research is curated and analyzed to determine the appropriate role of BZRAs in the course of pain management, and how prescribers might address their challenges.

\section{METHODS}

This is a narrative review and not a systematic review of the literature regarding the clinical use of BZRAs in the context of treating pain. It is based on relevant publications identified through an electronic search of PubMed (inception through February 2020), as well as a manual search of reference lists of identified articles, 26 guidelines, and the author's files. The primary objective was to determine the potential role of BZRAs as analgesics using search terms that combine "benzodiazepines", "non-benzodiazepines", "Z-drugs", and specific drug names along with the names of specific pain conditions. A secondary search was conducted pairing these agents with "anxiety", "sleep", "insomnia", "opioids", and "overdose". Clinical trials, reviews, and meta-analyses were considered if they described involvement of these medications in chronic pain when they compared BZRAs with other medications or placebo. Studies were excluded if they included fewer than 20 study subjects or primarily addressed acute pain, analgoanesthesia, intrathecal administration, or pediatric populations. A total of 9838 citations related to pain, 1735 related to anxiety, and 1096 related to sleep were retrieved. Abstracts and full-text articles of relevant titles were reviewed if available and in English. From these 336 publications were selected to form the core of this review: 189 related to chronic pain, 39 related to anxiety, and 33 related to sleep. This article is based on previously conducted studies and does not contain any studies with human participants or animals performed by the author.

\section{RESULTS}

\section{Benzodiazepine Use for Analgesia}

BZs have long been considered for their potential as primary or adjunctive analgesics [26]. While reduction in pain complaints have been observed with their use, it is not clear if this might be due mainly to modulation of affective responses [27, 28]. Preclinical research suggests that direct analgesia might be subserved by functional variants of the $\mathrm{GABA}_{\mathrm{A}} \mathrm{R}$ subunits $\alpha 2$ and $\alpha 3$ in the dorsal horn of the spinal cord $[29,30]$. In 1977 BZs were found to bind peripherally to what was subsequently identified as a distinct receptor, the translocator protein or TSPO, which among other functions appears to be involved in pain generation and sensitivity [31]. TSPO is not only expressed peripherally on mitochondrial membranes but also centrally on microglia $[32,33]$, which are activated and upregulated in spinal sites to develop and maintain certain pathologic pain conditions [34]. Animal research indicates that 
BZs may produce analgesia in part by promoting neurosteroid production through TSPO [35]. Despite such potential, this review identified data on only 29 of 111 pain conditions explored, and of these, the majority had evidence that was judged to be insufficient to provide conclusions about long-term use in chronic pain treatment.

Most studied was the analgesic response to BZs in musculoskeletal symptoms. In recent reviews of primary research investigations, BZs were found ineffective for low back pain and radiculopathy, yet posed significant risks for sedation [36-38]. Research on BZ efficacy for cervical, thoracic, and other spine pain conditions is insufficient. Though data is limited, it appears that BZs are ineffective for pain in rheumatoid arthritis [39, 40]. For pain associated with other rheumatologic or joint pathology including osteoarthritis, no data was identified.

Muscle pain can occur in the absence of muscle tension or result from hypertonia, spasm, and spasticity. With rare exception [41, 42], BZs (primarily diazepam) appear to be no better than placebo for muscular spasms, and other skeletal muscle relaxants are preferred [43-47]. This data, however, is old, not definitive, and generally only addressed spasm and not pain outcomes. Because of that, some experts [27] suggest that BZs remain an option in this context based on clinical experience.

Myofascial pain syndrome is characterized by regional discrete taut muscle bands that on palpation radiate pain along myofascial structures [48]. To date the minimal data available does not support the use of BZs in that condition [49]. Often confused with myofascial pain, fibromyalgia may involve trigger points as well [50] but is defined by tender points [48] and widespread (four-region), centralized (burning, electric) pain [51] due to unbalanced pronociceptive neurophysiology [52]. In a large internet survey $(N=2596)$ alprazolam, clonazepam, and zolpidem were perceived to be among the most effective medications in fibromyalgia [53]. However, this was not borne out in placebocontrolled investigations of alprazolam [54] or zolpidem [55], and Cochrane reviews were unable to identify research to support clonazepam efficacy [56, 57].

Although there is no research support for use of BZs in the musculoskeletal conditions above, there is demonstrable utility for painful hypertonia associated with stiff person syndrome. In this rare autoimmune disorder with variant clinical expressions (e.g., stiff limb syndrome, paraneoplastic), fluctuating muscle rigidity and spasms are due to continuous activation of muscle motor units [58-60]. Up to half of affected persons have psychological symptoms (data limited) [61, 62], and individuals may be misdiagnosed initially as having a primary anxiety disorder $[63,64]$. In stiff person syndrome, BZs are considered to be first-line therapy for muscular spasms and rigidity with good efficacy [58], though treatment-resistance and tachyphylaxis [59, 65] may require other approaches such as other GABAergic drugs, intravenous immunoglobulin administration, and plasmapheresis [58, 65]. Durability of benefit over time from BZs is uncertain, however.

Disabling muscle contractions can be driven by central neurologic processes as well. The dystonias are movement disorders presenting as sustained or repetitive, often painful muscle contractions. While small studies have included BZ therapy, none address analgesic outcomes nor met inclusion criteria for a recent review [66]. A range of medical conditions (e.g., stroke, spinal cord injury, multiple sclerosis) can result in spasticity, which can serve as a pain generator. Like spasms, spasticity is involuntary and uncontrolled, but unlike spasms, it is central in origin and involves repetitive contractions due to hyperexcitability of stretch reflexes [67]. Most research on BZ efficacy involves the use of diazepam, which depresses reactivity of flexor (low dose) and extensor (high dose) reflexes as well as enhances nighttime sedation [67], key to addressing spasticity. Research of oral BZs in spasticity is mixed and insufficient [68-71], however, and when benefit was seen, comparison trials favored other agents for functional and tolerability reasons [68, 72-76]. In a metaanalysis of 23 trials (total $N=2720$ ), diazepam was not recommended for spasticity in multiple sclerosis because of side effects and greater efficacy found with cannabinoids, botulinum 
toxin, and transcutaneous electrical stimulation [77]. Note that spasticity trials were not designed to examine pain endpoints so no firm conclusions can be drawn about analgesic efficacy [71].

Managing centralized pain, such as fibromyalgia, is particularly challenging. Reliance on opioids is problematic, since effective analgesic doses may be quite high and pose increased risk for adverse outcomes [78]. Alternatives, especially non-pharmaceutical therapies, are needed and sought after. Of 11 painful neuralgic and neuropathic conditions explored for this review, no data whatsoever was found for BZ use in eight. This was echoed by a Cochrane review which found no evaluable research on the use of clonazepam in neuropathic pain not otherwise specified [79]. From among these conditions, a search revealed only one paper that met inclusion criteria: a placebocontrolled trial in which lorazepam was ineffective for postherpetic neuralgia [80]. In a separate study, BZ use was associated with unsuccessful spinal cord stimulator trials [80]. Pain in multiple sclerosis is seen in at least $40 \%$ [81], and is not only related to spasticity for which BZs are discouraged [78] but is also driven by central sensitivity for which no BZ research was identified [72].

Head and facial pain may be nociceptive or centralized in type. There is conflicting data regarding the utility of BZs in chronic daily headache [82-85]. Insufficient evidence precludes drawing conclusions about their use in temporomandibular disorders (TMDs) [86] and trigeminal neuralgia $[87,88]$. On the other hand, numerous high-quality trials, systematic reviews, and meta-analyses support use of oral and topical clonazepam with as little as 3 weeks of therapy in burning mouth syndrome, a centralized pain condition seen in perimenopausal women who have xerostomia, dysgeusia, allodynia, and spontaneous burning pain in the oral cavity in the absence of an identified cause [89-91]. Results did not correlate with underlying psychopathology [92], and at least a 50\% reduction in symptoms was maintained in 70\% of patients for at least 6 months after 1 month's therapy while one-third experienced side effects that were transient and mild [93, 94]. In comparison trials, amitriptyline [95] and acupuncture [96] had similar efficacy, and lowlevel laser therapy was found to be superior [97].

BZs are poorly researched in chronic abdominal-pelvic pain. Many of these conditions involve central sensitivity $[98,99]$, as is the case for irritable bowel syndrome (IBS) which was the only abdominal disorder for which research on BZs was found among the 18 explored in this review. Considering their widespread use, it is surprising there are so few IBS trials involving BZs which are generally combined with anticholinergics. In short-term studies, symptomatic improvement can be seen, though it remains unclear if analgesic benefit might actually be indirectly derived from anxiolysis [100-104]. Long-term use in this chronic condition, however, has not been well studied and is discouraged [105]. Medical problems of the pelvis can be painful and due to peripheral and/or central mechanisms $[98,99,106]$. Limited information was identified for only two of nine painful conditions involving the pelvis and nearby structures researched here. Pelvic floor dysfunction is multifactorial, and data is limited and mixed with respect to BZ efficacy [107, 108]. In a single small study $(N=22)$, alprazolam did not improve symptoms of premenstrual syndrome [109].

\section{Benzodiazepine Receptor Agonist Use for Non-Analgesic Reasons}

BZRAs (BZs and Z-drugs) are frequently used for non-pain indications within pain management. A bidirectional relationship between pain and both anxiety and insomnia is well established in research with prevalence among persons with pain exceeding $50 \%[110,111]$. It is no surprise, then, that BZRAs are often considered.

BZs are indicated first-line for only a few conditions: alcohol withdrawal [112], status epilepticus [113], anesthesia for amnestic effect [114], and crisis anxiety without psychotic features [115]. For insomnia, cognitive behavioral therapy for insomnia (CBT-I) is first-line [116] with durable treatment effects lasting up to 18 months [117]. FDA-approved BZs (estazolam, flurazepam, quazepam, triazolam) and Z-drugs 
(zolpidem, zaleplon, eszopiclone) can be otherwise considered for short-term use (2-4 weeks) $[118,119]$. Though not first-line, BZs also have a limited role in certain intractable treatment-resistant seizure disorders (clobazam, clonazepam) [120].

Their role in anxiety is limited as well. Although short-term use in crisis anxiety is established [115], they are often prescribed inappropriately $[121,122]$, such as for ordinary anxiety that comes with normal life experiences when self-management strategies or brief therapy would suffice. BZs are either ineffective or contraindicated for anxiety associated with depression [123, 124], alcohol addiction following withdrawal [125], post-traumatic stress disorder [126, 127], and obsessive-compulsive disorder [127]. They can be considered when criteria for an anxiety disorder are met: anxiety lasting 6 months or more, functionally limiting, and disproportionate to the actual threat [128]. As effective as BZs [129], CBT is preferred as this avoids medication side effects and because sustained improvement has been observed for half of those treated on follow-up 8-14 years later [130]. However, since access to and benefit from CBT may be delayed, BZs can be prescribed as a bridge for 2-4 weeks for those who are functionally impaired. As BZs may interfere with efficacy of psychological therapies [131], discontinuation should proceed as soon as is feasible.

\section{DISCUSSION}

The purpose of this review is to define the boundaries of appropriate BZRA use in medical pain management. Efficacy in selected pain and non-pain conditions is outlined in Tables 1 and 2 , respectively. Unfortunately, BZRAs are often prescribed to those who are already at risk for poor outcomes [24]. Long-term (more than 4 weeks) efficacy and safety of BZRAs has not been demonstrated [124, 132]. There are three aspects to consider: (1) efficacy, (2) tolerability, and (3) physiologic dependence.

Sufficient evidence to support the use of BZs for analgesic purposes was found for only two of 111 pain conditions explored here: burning mouth syndrome and stiff person syndrome. Burning mouth syndrome is successfully treated with a short course of clonazepam (3-4 weeks), but durability of BZ efficacy in stiff person syndrome is unknown. When alternatives are inadequate, BZRAs used short-term (2-4 weeks) may benefit co-occurring insomnia and anxiety disorders. It is not unusual, however, for improvements to diminish over time [133-136], though this may be difficult to distinguish from worsening of the underlying conditions. Loss of efficacy may become apparent only upon cessation of the medication, which has also been observed in a clonazepam discontinuation study in seizure disorders [137]. Many clinicians may not recognize declining benefit because discontinuation prompts near-term increased symptoms and because this was not identified in earlier studies, perhaps because studied cohorts were too small or observed for too short a period of time [138].

BZRAs may have side effects that may or may not be evident [139-141]. Although true addiction is unlikely [142] other side effects are frequent and sometimes severe [133, 139]. Excess mortality overall [143], suicide [144], and accidental overdose fatalities [22] are associated with use. Some reactions with documented associations may be miscast as unrelated, such as akathisia, depersonalization, and even pain itself. Decrements in psychomotor and cognitive functions may occur gradually and be attributed to other causes or aging [145, 146]. Causation has not been confirmed, but correlation with dementia [147] and cancer $[148,149]$ has been identified. As with efficacy, BZRA involvement in symptom expression or functional declines may become apparent only upon deprescribing. Ashton, for example, found that anxiety and agoraphobia that developed during BZ use improved upon discontinuation [140]. It remains to be determined, though, whether or not there may be benzodiazepineinduced hyperanxiogenesis analogous to opioid-induced hyperalgesia.

Perhaps of greatest concern is the development of physiologic dependence which develops in $20-100 \%$ of those on BZs even at normal doses for more than a month [150-154]. Withdrawal symptoms may occur during medication 
Table 1 Benzodiazepine analgesic efficacy in selected pain conditions

\section{Pain condition}

Burning mouth syndrome

Stiff person syndrome

Multiple sclerosis

Dystonia

Neck pain

Low back pain

Sciatica (radiculopathy)

Rheumatoid arthritis

Fibromyalgia

Irritable bowel syndrome

Postherpetic neuralgia

Trigeminal neuralgia

Temporomandibular dysfunction

Pelvic floor dysfunction

Chronic daily tension-type headache

\section{Treatment outcomes}

Effective

Effective

Effective-other treatments favored

Evidence insufficient

Evidence insufficient

Ineffective

Ineffective

Ineffective

Small studies: probably ineffective

Short-term benefit, long term not recommended

One small study: lorazepam ineffective

Evidence insufficient

Evidence insufficient

Evidence mixed

Evidence mixed

Table 2 Benzodiazepine or Z-drug efficacy in selected non-pain conditions

\section{Non-pain condition}

Procedural amnestic/analgoanesthesia

Status epilepticus

Anxiety: Crisis without psychosis

Anxiety: Mild-moderate

Anxiety: Anxiety disorder

Anxiety: Associated with depression

Anxiety: Associated with PTSD

Anxiety: Associated with OCD

Anxiety: Associated with substance use disorder

Insomnia

Selected intractable seizures

\section{Treatment outcomes}

Effective 1st line for one-time use

Effective 1st line for one-time use

Effective 1st line for one-time use

Not indicated

Effective 2nd line for short-term use (2-4 weeks)

Not indicated

Contraindicated

Ineffective

Effective 1st line for BZRA, alcohol withdrawal

Otherwise contraindicated

Effective 2nd line for short-term use (2-4 weeks) Effective 2 nd line for adjunctive use 
Table 3 Benzodiazepine receptor agonists: best practice recommendations

1. Limit initiation to clear indications

2. Limit duration of use to $2-4$ weeks

3. For those on BZRAs long term do not

(1) Assume symptoms indicate a need to increase the dose

(2) Assume difficulties mean addiction-this is rare

4. Offer deprescribing to all who are using BZRAs $>4$ weeks

5. For those who decline the offer, continue to monitor for and manage adverse reactions

6. For those who accept the offer

(1) First: educate, plan, establish support

(2) Initiate CBT prior to tapering

(3) Consider substituting with a long-acting BZRA prior to tapering

(4) Taper slowly anticipating it may take 12-18 months or longer

(5) Tapering amounts and intervals are best patient-directed

(6) Avoid up-dosing BZRAs or as-needed doses

7. Regard discontinuation symptoms seriously even if sounding peculiar

8. Regard patient reports seriously-they are the experts on their own experience

9. Support patients with ongoing symptoms that may continue months or years

use (interdose or tolerance withdrawal) [139], after as little as 2-6 weeks of exposure [155], and be quite severe $[133-135,139]$. Symptom expression while tapering may be attributed to relapse or rebound of the underlying condition [156]. Their dramatic and widely fluctuating nature [139] may prompt consideration of alternative diagnoses, such as somatic symptom disorder [128]. While the latter may technically be applied to conditions with defined pathophysiologic explanations, in practice assigning this diagnosis and other related terms (e.g., functional, catastrophizing) is pejorative, casts doubt on symptom validity, and implies patient self-culpability [98]. In addition, this may impart a sense of therapeutic nihilism, limiting prescriber motivation to work towards solutions. These are bone fide symptoms that are neurophysiologically based and possibly due to oxidative stress described in a hypothesis by LaCorte [157]. Protracted, sometimes severe symptoms are seen in an estimated $10-15 \%$ of patients [139], and because they may persist indefinitely, the term "benzodiazepine injury syndrome" may be a more accurate descriptor than "withdrawal", as the latter implies ultimate resolution.

Patients are probably not benefited by avoiding or delaying discontinuation [158]. Abrupt cessation is dangerous, and slow tapering over $12-18$ months is recommended along with careful planning and support. Success is improved with the use of CBT, (substituted) long-acting BZRAs, and perhaps adjunctive medications. A description of this process is beyond the scope of this paper and is detailed in the Ashton Manual [139] and elsewhere [159].

\section{CONCLUSIONS}

Medical providers are challenged as to how to address the complexities of pain. A multimodal, multidisciplinary approach is indicated, and 
non-pharmacologic options are often preferred, though medications may be necessary. Far less is known about the role of benzodiazepine receptor agonists (benzodiazepines and the related Z-drugs) than other agents like opioids in pain management. Evidence supports a very limited role for their use in co-occurring anxiety disorders and insomnia. This review identified demonstrated analgesic value for two painful conditions: burning mouth syndrome and stiff person syndrome. For the other 109 conditions examined, evidence was either absent or insufficient to draw any conclusions about the longterm efficacy necessary in addressing the chronic nature of the pain. A number of best practice recommendations can be made (Table 3) to include offering discontinuation to patients on these medications for over a month by means of a slow tapering process that may take 12-18 months or more to complete. Unusual and persistent symptoms during and/or after tapering (benzodiazepine injury syndrome) are valid and are not to be minimized or discounted. Affected individuals need ongoing support and therapeutic effort.

\section{ACKNOWLEDGEMENTS}

Funding. This research has been funded by the Alliance for Benzodiazepine Best Practices with an unconditional grant. No Rapid Service Fee or Open Access fees were received by the journal for the publication of this article.

Authorship. The author meets the International Committee of Medical Journal Editors (ICMJE) criteria for authorship for this article, takes responsibility for the integrity of the work as a whole, and has given his approval for this version to be published.

Author Contributions. As well as authorship of this paper, Steven Wright, MD, was solely involved in the design of the review, search and analysis of the background literature, and reviewed and approved the final version of the manuscript.
Disclosures. Steven Wright, MD, serves as medical consultant for the Alliance for Benzodiazepine Best Practices and is a member of the journal's Editorial Board.

Compliance with Ethics Guidelines. This article is based on previously conducted studies and does not contain any studies with human participants or animals performed by the author.

Data Availability. Data sharing is not applicable to this article as no datasets were generated or analyzed during the current study.

Open Access. This article is licensed under a Creative Commons Attribution-NonCommercial 4.0 International License, which permits any non-commercial use, sharing, adaptation, distribution and reproduction in any medium or format, as long as you give appropriate credit to the original author(s) and the source, provide a link to the Creative Commons licence, and indicate if changes were made. The images or other third party material in this article are included in the article's Creative Commons licence, unless indicated otherwise in a credit line to the material. If material is not included in the article's Creative Commons licence and your intended use is not permitted by statutory regulation or exceeds the permitted use, you will need to obtain permission directly from the copyright holder. To view a copy of this licence, visit http://creativecommons.org/licenses/by$\mathrm{nc} / 4.0 /$.

\section{REFERENCES}

1. Tsang A, Von Korff M, Lee S, et al. Common chronic pain conditions in developed and developing countries: gender and age differences and comorbidity with depression-anxiety disorders. J Pain. 2008;9(10):883-91.

2. Kennedy J, Roll JM, Schraudner T, et al. Prevalence of persistent pain in the US adult population: new data from the 2010 national health interview survey. J Pain. 2014;15(10):979-84. 
3. Ngo DH, Vo TS. An updated review on pharmaceutical properties of gamma-aminobutyric acid. Molecules. 2019;24(15):E2678.

4. Griffin CE, Kaye AM, Bueno FR, Kaye AD. Benzodiazepine pharmacology and central nervous systemmediated effects. Ochsner J. 2013;13(2):214-23.

5. Earl DE, Tietz EI. Inhibition of recombinant L-type voltage-gated calcium channels by positive allosteric modulators of $\mathrm{GABA}_{\mathrm{A}}$ receptors. J Pharmacol Exp Ther. 2011;337(1):301-11.

6. Yuan CS, Mehendale S, Xiao Y, et al. The gammaaminobutyric acidergic effects of valerian and valerenic acid on rat brainstem neuronal activity. Anesth Analg. 2004;98(2):353-8.

7. Lile JA, Kelly TH, Hays LR. Separate and combined effects of the GABAA positive allosteric modulator diazepam and $\triangle 9$-THC in humans discriminating 49-THC. Drug Alcohol Depend. 2014;143:141-8.

8. Agarwal SD, Bruce E, Landon BE. Patterns in outpatient benzodiazepine prescribing in the United States. JAMA Netw Open. 2019;2(1):e187399.

9. Bachhuber MA, Hennessy S, Cunningham CO, Starrels JL. Increasing benzodiazepine prescriptions and overdose mortality in the United States, 1996-2013. Am J Pub Health. 2016;106:686-8.

10. Blanco C, Han B, Jones CM, et al. Prevalence and correlates of benzodiazepine use, misuse, and use disorders among adults in the United States. J Clin Psychiatry. 2018;79(6):1812174.

11. Maust DT, Lin LA, Blow FC. Benzodiazepine use and misuse among adults in the United States. Psychiatr Serv. 2019;70(2):97-106.

12. Bohnert ASB, Guy GP, Losby JL. Opioid prescribing in the United States before and after the Centers for Disease Control and Prevention's 2016 Opioid Guideline. Ann Intern Med. 2018;169(6):367-75.

13. Carico R, Zhao X, Thorpe CT, et al. Receipt of overlapping opioid and benzodiazepine prescriptions among veterans dually enrolled in Medicare Part D and the Department of Veterans Affairs: a cross-sectional study. Ann Intern Med. 2018;169(9): 593-601.

14. Guy G, Zhang K, Halpin J, Sargent W. An examination of concurrent opioid and benzodiazepine prescribing in 9 states, 2015. Am J Prevent Med. 2019;57(5):629-36.

15. Hwang CS, Kang EM, Kornegay CJ, et al. Trends in the concomitant prescribing of opioids and benzodiazepines, 2002-2014. Am J Prev Med. 2016;51(2): 151-60.
16. McClure FL, Niles JK, Kaufman HW, Gudin J. Concurrent use of opioids and benzodiazepines: evaluation of prescription drug monitoring by a United States laboratory. J Addict Med. 2017;11(6):420-6.

17. Sun EC, Dixit A, Humphreys K, et al. Association between concurrent use of prescription opioids and benzodiazepines and overdose: retrospective analysis. BMJ. 2017;356:j760.

18. Nielsen S, Lintzeris N, Bruno R, et al. Benzodiazepine use among chronic pain patients prescribed opioids: associations with pain, physical and mental health, and health service utilization. Pain Med. 2015;16(2):356-66.

19. Yarborough BJH, Stumbo SP, Stoneburner A, et al. Correlates of benzodiazepine use and adverse outcomes among patients with chronic pain prescribed long-term opioid therapy. Pain Med. 2019;20(6): 1148-55.

20. Hirschtritta ME, Delucchib KL, Olfson M. Outpatient, combined use of opioid and benzodiazepine medications in the United States, 1993-2014. Prevent Med Rep. 2018;9:49-544.

21. Chen LH, Hedegaard H, Warner M. Drug-poisoning deaths Involving opioid analgesics: United States, 1999-2011. NCHS Data Brief. 2014;166:1-8.

22. Mattson CL, O'Donnell J, Kariisa M, et al. Opportunities to prevent overdose deaths involving prescription and illicit opioids, 11 states, July 2016-June 2017. MMWR. 2018;67(34):945-51.

23. Dasgupta N, Funk MJ, Proescholdbell S, et al. Cohort study of the impact of high-dose opioid analgesics on overdose mortality. Pain Med. 2016;17(1):85-988.

24. Kroll DS, Niece HR, Barsky AJ, Linder JA. Benzodiazepines are prescribed more frequently to patients already at risk for benzodiazepine-related adverse events in primary care. J Gen Intern Med. 2016;31: 1027-34.

25. US Food and Drug Administration. FDA News Release: FDA requires strong warnings for opioid analgesics, prescription opioid cough products, and benzodiazepine labeling related to serious risks and death from combined use. 2016. https://www.fda.gov/newsevents/press-announcements/fda-requires-strongwarnings-opioid-analgesics-prescription-opioidcough-products-and-benzodiazepine. Accessed 5 Apr 2020.

26. Goldstein FJ. Adjuncts to opioid therapy. J Am Osteopath Assoc. 2002;102(9 Suppl 3):S15-21. 
27. Reddy S, Patt RB. The benzodiazepines as adjuvant analgesics. J Pain Symptom Manage. 1994;9(8): 510-4.

28. Farrar JT, Portnoy RK. Neuropathic cancer pain: the role of adjuvant analgesics. Oncology. 2001;15(11): 1435-42 (1445; Abstract).

29. Munro G, Erichsen HK, Rae MG, Mirza NR. A question of balance - positive versus negative allosteric modulation of $\mathrm{GABA}_{\mathrm{A}}$ receptor subtypes as a driver of analgesic efficacy in rat models of inflammatory and neuropathic pain. Neuropharmacology. 2011;61(1-2):121-32.

30. Trincavelli ML, Da Pozzo E, Daniele S, Martini C. The $\mathrm{GABA}_{\mathrm{A}}$-BZR complex as target for the development of anxiolytic drugs. Curr Top Med Chem. 2012;12(4):254-69.

31. Hernstadt H, Wang S, Lim G, Mao J. Spinal translocator protein (TSPO) modulates pain behavior in rats with CFA-induced monoarthritis. Brain Res. 2009;1286:42-52.

32. Da Pozzo E, Giacomelli C, Barresi E, et al. Targeting the 18-kDa translocator protein: recent perspectives for neuroprotection. Biochem Soc Trans. 2015;43(4):559-65.

33. Bonsack F, Sukumari-Ramesh S. TSPO: an evolutionarily conserved protein with elusive functions. Int J Mol Sci. 2018;19(6):E1694.

34. Watkins LR, Maier SF. Beyond neurons: evidence that immune and glial cells contribute to pathological pain states. Physiol Rev. 2002;82:981-1011.

35. Chen SL, Zang Y, Zheng WH, et al. Inhibition of neuropathic pain by a single intraperitoneal injection of diazepam in the rat: possible role of neurosteroids. Chin J Physiol. 2016;59(1):9-20.

36. Abdel Shaheed C, Maher CG, Williams KA, McLachlan AJ. Efficacy and tolerability of muscle relaxants for low back pain: systematic review and meta-analysis. Eur J Pain. 2017;21(2):228-37.

37. Chou R, Deyo R, Friedly J, et al. Systemic pharmacologic therapies for low back pain: a systematic review for an American College of Physicians Clinical Practice Guideline. Ann Int Med. 2017;166(7): 480-92.

38. Chou R, Deyo R, Friedly J, et al. Noninvasive treatments for low back pain. Comparative Effectiveness Review No. 169. AHRQ Publication No. 16-EHC004EF. Rockville, MD: Agency for Healthcare Research and Quality. 2016. https://www.ncbi.nlm.nih.gov/ books/NBK350276/. Accessed 5 Apr 2020.
39. Hardo PG, Kennedy TD. Night sedation and arthritic pain. J R Soc Med. 1991;84(2):73-5.

40. Richards BL, Whittle SL, Buchbinder R. Muscle relaxants for pain management in rheumatoid arthritis. Cochrane Database Syst Rev. 2012;1: CD008922.

41. Hollister LE, Conley FK, Britt RH, Shuer L. Longterm use of diazepam. JAMA. 1981;246(14): 1568-70.

42. Singer E, Dionne R. A controlled evaluation of ibuprofen and diazepam for chronic orofacial muscle pain. J Orofac Pain. 1997;11(2):139-46.

43. Elenbaas JK. Centrally acting oral skeletal muscle relaxants. Am J Hosp Pharm. 1980;37(10):1313-23.

44. Fryda-Kaurimsky Z, Müller-Fassbender H. Tizanidine (DS 103-282) in the treatment of acute paravertebral muscle spasm: a controlled trial comparing tizanidine and diazepam. J Int Med Res. 1981;9(6):501-5.

45. Hennies OL. A new skeletal muscle relaxant (DS 103-282) compared to diazepam in the treatment of muscle spasm of local origin. J Int Med Res. 1981;9(1):62-8.

46. Katz WA, Dube J. Cyclobenzaprine in the treatment of acute muscle spasm: review of a decade of clinical experience. Clin Ther. 1988;10(2):216-28.

47. Stanko JR. Review of oral skeletal muscle relaxants for the craniomandibular disorder (CMD) practitioner. Cranio. 1990;8(3):234-43.

48. Schneider MJ. Tender points/fibromyalgia vs trigger points/myofascial pain syndrome: a need for clarity in terminology and differential diagnosis. J Manipulative Physiol Ther. 1995;18(6):398-406.

49. Herman CR, Schiffman EL, Look JO, Rindal DB. The effectiveness of adding pharmacologic treatment with clonazepam or cyclobenzaprine to patient education and self-care for the treatment of jaw pain upon awakening: a randomized clinical trial. J Orofac Pain. 2002;16(1):64-70.

50. Wolfe F, Simons DG, Friction J, et al. The fibromyalgia and myofascial pain syndromes: a preliminary study of tender points and trigger points in persons with fibromyalgia, myofascial pain syndrome and no disease. J Rheumatol. 1992;19(6):944-51.

51. Wolfe F, Butler SH, Fitzcharles M, et al. Revised chronic widespread pain criteria: development from and integration with fibromyalgia criteria. Scand J Pain. 2019;20(1):77-86. 
52. Clauw DJ. Fibromyalgia: clinical review. JAMA. 2014;311(15):1547-55.

53. Bennett RM, Jones J, Turk DC, et al. An internet survey of 2,596 people with fibromyalgia. BMC Musculoskelet Disord. 2007;8:27.

54. Kravitz HM, Katz RS, Helmke N, et al. Alprazolam and ibuprofen in the treatment of fibromyalgia report of a double-blind placebo-controlled study. J Musculoskeletal Pain. 1994;2(1):3-27.

55. Moldofsky H, Lue FA, Mously C, et al. The effect of zolpidem in patients with fibromyalgia: a dose ranging, double blind, placebo controlled, modified crossover study. J Rheumatol. 1996;23(3):529-33.

56. Corrigan R, Derry S, Wiffen PJ, Moore RA. Clonazepam for neuropathic pain and fibromyalgia in adults. Cochrane Database Syst Rev. 2012;5:CD. 9486.

57. Wiffen PJ, Derry S, Moore RA, et al. Antiepileptic drugs for neuropathic pain and fibromyalgia - an overview of Cochrane reviews. Cochrane Database Syst Rev. 2013;2013(11):10567.

58. Bhatti AB, Gazali ZA. Recent advances and review on treatment of stiff person syndrome in adults and pediatric patients. Cureus. 2015;7(12):e427.

59. Barker RA, Revesz T, Thom M, et al. Review of 23 patients affected by the stiff man syndrome: clinical subdivision into stiff trunk (man) syndrome, stiff limb syndrome, and progressive encephalomyelitis with rigidity. J Neurol Neurosurg Psychiatry. 1998;65(5):633-40.

60. Brown P, Marsden CD. The stiff man and stiff man plus syndromes. J Neurol. 1999;246(8):648-52.

61. Tinsley JA, Barth EM, Black JL, Williams DE. Psychiatric consultations in stiff-man syndrome. J Clin Psychiatry. 1997;58(10):444-9.

62. Henningsen P, Meinck HM. Specific phobia is a frequent non-motor feature in stiff man syndrome. J Neurol Neurosurg Psychiatry. 2003;74(4):462-5.

63. Souissi MA, Bellakhal S, Gharbi E, et al. A stiff person syndrome misdiagnosed as a psychiatric illness. Curr Rheumatol Rev. 2019. https://doi.org/10.2174/ 1573397115666191116101240 .

64. Cervantes CE, Lee Lau H, Binazir TA, et al. Why it is not always anxiety: a tough diagnosis of stiff person syndrome. Case Rep Neurol Med. 2017;2017: 7431092 .

65. Zdziarski P. A case of stiff person syndrome: immunomodulatory effect of benzodiazepines: successful rituximab and tizanidine therapy. Medicine (Baltimore). 2015;94(23):e954.

66. Fehlings D, Brown L, Harvey A, et al. Pharmacological and neurosurgical interventions for managing dystonia in cerebral palsy: a systematic review. Dev Med Child Neurol. 2018;60(4):356-66.

67. Chang E, Ghosh N, Yanni D, et al. A review of spasticity treatments: pharmacological and interventional approaches. Crit Rev Phys Rehabil Med. 2013;25(1-2):11-22.

68. Kamen L, Henney HR, Runyan JD. A practical overview of tizanidine use for spasticity secondary to multiple sclerosis, stroke, and spinal cord injury. Curr Med Res Opin. 2008;24(2):425-39.

69. Lindsay C, Kouzouna A, Simcox C, Pandyan AD. Pharmacological interventions other than botulinum toxin for spasticity after stroke. Cochrane Database Syst Rev. 2016;10:10362.

70. Taricco M, Pagliacci MC, Telaro E, Adone R. Pharmacological interventions for spasticity following spinal cord injury: results of a Cochrane systematic review. Eura Medicophys. 2006;42(1):5-15.

71. Beard S, Hunn A, Wight J. Treatments for spasticity and pain in multiple sclerosis: a systematic review. Health Technol Assess. 2003;7(40):iii (ix-X, 1-111).

72. Bes A, Eyssette M, Pierrot-Deseilligny E, et al. A multi-centre, double-blind trial of tizanidine, a new antispastic agent, in spasticity associated with hemiplegia. Curr Med Res Opin. 1988;10(10): 709-18.

73. Otero-Romero S, Sastre-Garriga J, Comi G, et al. Pharmacological management of spasticity in multiple sclerosis: systematic review and consensus paper. Mult Scler. 2016;22(11):1386-96.

74. Glass A, Hannah A. A comparison of dantrolene sodium and diazepam in the treatment of spasticity. Paraplegia. 1974;12:170-4.

75. Groves L, Shellenberger MK, Davis CS. Tizanidine treatment of spasticity: a meta-analysis of controlled, double-blind, comparative studies with baclofen and diazepam. Adv Ther. 1998;15(4): 241-51.

76. Roussan M, Terrence C, Fromm G. Baclofen versus diazepam for the treatment of spasticity and longterm follow-up of baclofen therapy. Pharmatherapeutica. 1985;4:278-84.

77. Fu X, Wang Y, Wang C, et al. A mixed treatment comparison on efficacy and safety of treatments for spasticity caused by multiple sclerosis: a systematic 
review and network meta-analysis. Clin Rehabil. 2018;32(6):713-21.

78. Finnerup NB, Attal N, Haroutounian S, et al. Pharmacotherapy for neuropathic pain in adults: a systematic review and meta-analysis. Lancet Neurol. 2015;14(2):162-73.

79. Corrigan R, Derry S, Wiffen PJ, Moore RA. Clonazepam for neuropathic pain and fibromyalgia in adults. Cochrane Database Syst Rev. 2012;2012(5): 9486.

80. Max MB, Schafer SC, Culnane M, et al. Amitriptyline, but not lorazepam, relieves postherpetic neuralgia. Neurology. 1988;38(9):1427-32.

81. Solaro C, Uccelli MM. Pharmacological management of pain in patients with multiple sclerosis. Drugs. 2010;70(10):1245-54.

82. Shukla R, Nag D, Ahuja RC. Alprazolam in chronic tension type headache. J Assoc Physicians India. 1996;44:641-4.

83. Verhagen AP, Damen L, Berger MY, et al. Lack of benefit for prophylactic drugs of tension-type headache in adults: a systematic review. Fam Pract. 2010;27(2):151-65.

84. Krishnan A, Silver N. Headache (chronic tensiontype). BMJ Clin Evid. 2009;2009:1205.

85. Hackett GI, Boddie HG, Harrison P. Chronic muscle contraction headache: the importance of depression and anxiety. J R Soc Med. 1987;80(11):689-91.

86. Mujakperuo HR, Watson M, Morrison R, Macfarlane TV. Pharmacological interventions for pain in patients with temporomandibular disorders. Cochrane Database Syst Rev. 2010;2010(10):4715.

87. Sindrup SH, Jensen TS. Pharmacotherapy of trigeminal neuralgia. Clin J Pain. 2002;18(1):22-7.

88. Martin WJ, Forouzanfar T. The efficacy of anticonvulsants on orofacial pain: a systematic review. Oral Surg Oral Med Oral Pathol Oral Radiol Endod. 2011;111(5):627-33.

89. Cui Y, Xu H, Chen FM, et al. Efficacy evaluation of clonazepam for symptom remission in burning mouth syndrome: a meta-analysis. Oral Dis. 2016;22(6):503-11.

90. Fischoff DK, Spivakovsky S. Little evidence to support or refute interventions for the management of burning mouth syndrome. Evid Based Dent. 2017;18(2):57-8.
91. Liu YF, Kim Y, Yoo T, et al. Burning mouth syndrome: a systematic review of treatments. Oral Dis. 2018;24(3):325-34.

92. Barker KE, Batstone MD, Savage NW. Comparison of treatment modalities in burning mouth syndrome. Aust Dent J. 2009;54(4):300-5.

93. de Rivera R, Campillo E, López-López J, ChimenosKüstner E. Response to topical clonazepam in patients with burning mouth syndrome: a clinical study. Bull Group Int Rech Sci Stomatol Odontol. 2010;49(1):19-29.

94. Amos K, Yeoh SC, Farah CS. Combined topical and systemic clonazepam therapy for the management of burning mouth syndrome: a retrospective pilot study. J Orofac Pain. 2011;25(2):125-30.

95. Fenelon M, Quinque E, Arrive E, et al. Pain-relieving effects of clonazepam and amitriptyline in burning mouth syndrome: a retrospective study. Int J Oral Maxillofac Surg. 2017;46(11):1505-11.

96. Jurisic Kvesic A, Zavoreo I, Basic Kes V, et al. The effectiveness of acupuncture versus clonazepam in patients with burning mouth syndrome. Acupunct Med. 2015;33(4):289-92.

97. Arduino PG, Cafaro A, Garrone M, et al. A randomized pilot study to assess the safety and the value of low-level laser therapy versus clonazepam in patients with burning mouth syndrome. Lasers Med Sci. 2016;31(4):811-6.

98. Yunus MB. Central sensitivity syndromes: a new paradigm and group nosology for fibromyalgia and overlapping conditions, and the related issue of disease versus illness. Semin Arthritis Rheum. 2008;37(6):339-52.

99. Yunus MB. Editorial review: an update on central sensitivity syndromes and the issues of nosology and psychobiology. Curr Rheumatol Rev. 2015;11(2):70-85.

100. Chen L, Ilham SJ, Feng B. Pharmacological approach for managing pain in irritable bowel syndrome: a review article. Anesth Pain Med. 2017;7(2):e42747.

101. Camilleri M. Current and future pharmacological treatments for diarrhea-predominant irritable bowel syndrome. Expert Opin Pharmacother. 2013;14(9): 1151-60.

102. Mollica G, Manno G. Otilonium bromide-diazepam in the treatment of the irritable colon. A controlled study versus otilonium bromide. Clin Ter. 1992;141(8):129-34. 
103. Lydiard RB. Irritable bowel syndrome, anxiety, and depression: what are the links? J Clin Psychiatry. 2001;62(Suppl 8):38-45.

104. Salari P, Abdollahi M. Systematic review of modulators of benzodiazepine receptors in irritable bowel syndrome: is there hope? World J Gastroenterol. 2011;17(38):4251-7.

105. Saito YA, Fox JC. Management of functional abdominal pain. Curr Treat Options Gastroenterol. 2004;7(4):279-90.

106. Carey ET, Till SR, As-Sanie S. Pharmacological management of chronic pelvic pain in women. Drugs. 2017;77(3):285-301.

107. Chiarioni G, Asteria C, Whitehead WE. Chronic proctalgia and chronic pelvic pain syndromes: new etiologic insights and treatment options. World J Gastroenterol. 2011;17(40):4447-55.

108. Crisp CC, Vaccaro CM, Estanol MV, et al. Intravaginal diazepam for high-tone pelvic floor dysfunction: a randomized placebo-controlled trial. Int Urogynecol J. 2013;24(11):1915-23.

109. Schmidt PJ, Grover GN, Rubinow DR. Alprazolam in the treatment of premenstrual syndrome. A doubleblind, placebo-controlled trial. Arch Gen Psychiatry. 1993;50(6):467-73.

110. Sagheer MA, Khan MF, Sharif S. Association between chronic low back pain, anxiety and depression in patients at a tertiary care center. J Pak Med Assoc. 2013;63(6):688-90.

111. Alsaadi SM, McAuley JH, Hush JM, Maher CG. Prevalence of sleep disturbance in patients with low back pain. Eur Spine J. 2011;20(5):737-43.

112. Askgaard G, Pottegård A, Fink-Jensen A. Benzodiazepines should still be first-line treatment for alcohol withdrawal. Ugeskr Laeger. 2017;179(3): V07160465..

113. Prasad M, Krishnan PR, Sequeira R, Al-Roomi K. Anticonvulsant therapy for status epilepticus. Cochrane Database Syst Rev. 2014;(9):CD003723. .

114. Devabhakthuni S, Armahizer MJ, Dasta JF, Kane-Gill SL. Analgosedation: a paradigm shift in intensive care unit sedation practice. Ann Pharmacother. 2012;46(4):530-40.

115. Allen $\mathrm{MH}$, Currier GW, Carpenter D, et al. The expert consensus guideline series. Treatment of behavioral emergencies 2005. J Psychiatr Pract. 2005;11(Suppl 1):5-108 (quiz 110-2).

116. Trauer JM, Qian MY, Doyle JS, et al. Cognitive behavioral therapy for chronic insomnia: a systematic review and meta-analysis. Ann Intern Med. 2015;163(3):191-204.

117. Geiger-Brown JM, Rogers VE, Liu W, et al. Cognitive behavioral therapy in persons with comorbid insomnia: a meta-analysis. Sleep Med Rev. 2015;23: 54-67.

118. [No authors listed]. Sleep complaints: whenever possible, avoid the use of sleeping pills. Prescrire Int. 2008;17(97):206-12.

119. Sateia MJ, Buysse DJ, Krystal AD, et al. Clinical practice guideline for the pharmacologic treatment of chronic insomnia in adults: an American Academy of Sleep Medicine Clinical Practice Guideline. J Clin Sleep Med. 2017;13(2):307-49.

120. National Institute for Health and Clinical Excellence: Guidance. The epilepsies: the diagnosis and management of the epilepsies in adults and children in primary and secondary care: pharmacological update of clinical guideline 20. 2012. https:// www.ncbi.nlm.nih.gov/books/NBK247130/. Accessed 5 Apr 2020.

121. Cook JM, Marshall R, Masci C, Coyne JC. Physicians' perspectives on prescribing benzodiazepines for older adults: a qualitative study. J Gen Intern Med. 2007;22(3):303-7. https://doi.org/10.1007/ s11606-006-0021-3.

122. Buck MD, Atreja A, Brunker CP, et al. Potentially inappropriate medication prescribing in outpatient practices: prevalence and patient characteristics based on electronic health records. Am J Geriatr Pharmacother. 2009;7(2):84-92.

123. Bushnell GA, Stürmer T, Gaynes BN, et al. Simultaneous antidepressant and benzodiazepine new use and subsequent long-term benzodiazepine use in adults with depression, United States, 2001-2014. JAMA Psychiatry. 2017;74(7):747-55.

124. Pélissolo A, Maniere F, Boutges B, et al. Anxiety and depressive disorders in 4,425 long term benzodiazepine users in general practice. Encephale. 2007;33(1):32-8.

125. Ilomäki J, Gnjidic D, Hilmer SN, et al. Psychotropic drug use and alcohol drinking in communitydwelling older Australian men: the CHAMP study. Drug Alcohol Rev. 2013;32(2):218-22.

126. Berger W, Mendlowicz MV, Marques-Portella C, et al. Pharmacologic alternatives to antidepressants in posttraumatic stress disorder: a systematic review. Prog Neuropsychopharmacol Biol Psychiatry. 2009;33(2):169-80.

127. Dell'osso B, Lader M. Do benzodiazepines still deserve a major role in the treatment of psychiatric 
disorders? A critical reappraisal. Eur Psychiatry. 2013;28(1):7-20.

128. American Psychiatric Association. Substance-related and addictive disorders. In: Diagnostic and statistical manual of mental disorders, 5th Edition. Arlington: American Psychiatric Association. 2013.

129. Imai H, Tajika A, Chen P, Pompoli A, Furukawa TA. Psychological therapies versus pharmacological interventions for panic disorder with or without agoraphobia in adults. Cochrane Database Syst Rev. 2016;10:CD11170.

130. Durham RC, Chambers JA, MacDonald RR, et al. Does cognitive-behavioral therapy influence the long-term outcome of generalized anxiety disorder? An 8-14 year follow-up of two clinical trials. Psychol Med. 2003;33(3):499-509.

131. Klosko JS, Barlow DH, Tassinari R, Cerny JA. A comparison of alprazolam and behavior therapy in treatment of panic disorder. J Consult Clin Psychol. 1990;58(1):77-84.

132. van Balkom AJ, de Beurs E, Koele P, et al. Long-term benzodiazepine use is associated with smaller treatment gain in panic disorder with agoraphobia. J Nerv Ment Dis. 1996;184(2):133-5.

133. Fixsen AM, Ridge D. Stories of hell and healing: internet users' construction of benzodiazepine distress and withdrawal. Qual Health Res. 2017;27(13): 2030-41.

134. Pittman CM, Youngs W, Karle E. Social networking and benzodiazepine withdrawal: the realities of dependence and the necessity of support. In: Presented at the 33rd Annual National Conference of the Anxiety and Depression Association of America, La Jolla, California. 2013. https://adaa.org/sites/ default/files/Pittman121.pdf. Accessed 5 Apr 2020.

135. Young A. Survey of benzodiazepine withdrawal outcomes of an internet benzodiazepine group. 2007. http://www.benzosupport.org/survey_contents.htm. Accessed 5 Apr 2020.

136. Romach MK, Busto UE, Sobell LC, et al. Long-term alprazolam use: abuse, dependence or treatment? Psychopharmacol Bull. 1991;27(3):391-5.

137. Specht U, Boenigk HE, Wolf P. Discontinuation of clonazepam after long-term treatment. Epilepsia. 1989;30(4):458-63.

138. Fava GA. Fading of therapeutic effects of alprazolam in agoraphobia. Case reports. Prog Neuropsychopharmacol Biol Psychiatry. 1988;12(1):109-12.
139. Ashton H. The Ashton manual: benzodiazepineshow they work and how to withdraw. 2002. https:// www.benzo.org.uk/manual/. Accessed 5 Apr 2020.

140. Ashton H. Benzodiazepine withdrawal: outcome in 50 patients. Br J Addict. 1987;82:655-71.

141. Brandt J, Leong C. Benzodiazepines and Z-Drugs: an updated review of major adverse outcomes reported on in epidemiologic research. Drugs $\mathrm{R} D$. 2017;17(4):493-507.

142. Becker WC, Fiellin DA, Desai RA. Non-medical use, abuse and dependence on sedatives and tranquilizers among US adults: psychiatric and socio-demographic correlates. Drug Alcohol Depend. 2007;90(2-3):280-7.

143. Hausken AM, Skurtveit S, Tverdal A. Use of anxiolytic or hypnotic drugs and total mortality in a general middle-aged population. Pharmacoepidemiol Drug Saf. 2007;16(8):913-8.

144. Dodds TJ. Prescribed benzodiazepines and suicide risk: a review of the literature. Prim Care Companion CNS Disord. 2017. https://doi.org/10.4088/ PCC.16r02037

145. Barker MJ, Greenwood KM, Jackson M, Crowe SF. Cognitive effects of long-term benzodiazepine use: a meta-analysis. CNS Drugs. 2004;18(1):37-48.

146. Gray SL, LaCroix AZ, Hanlon JT, et al. Benzodiazepine use and physical disability in communitydwelling older adults. J Am Geriatr Soc. 2006;54(2): 224-30.

147. Billioti de Gage S, Boride Y, Ducret T, et al. Benzodiazepine use and risk of Alzheimer's disease: casecontrol study. BMJ. 2014;349:5205.

148. Iqbal U, Nguyen P-A, Syed-Abdul S, et al. Is longterm use of benzodiazepine a risk for cancer? Medicine (Baltimore). 2015;94(6):e483.

149. Kripke DF, Langer RD, Kline LE. Hypnotics' association with mortality or cancer: a matched cohort study. BMJ Open. 2012;2:e000850.

150. Rickels K, Schweizer E, Case WG, Greenblatt DJ. Long-term therapeutic use of benzodiazepines. I. Effects of abrupt discontinuation. Arch Gen Psychiatry. 1990;47(10):899-907.

151. Tyrer P, Owen R, Dawling S. Gradual withdrawal of diazepam after long-term therapy. Lancet. 1983;1(8339):1402-6.

152. de las Cuevas C, Sanz E, de la Fuente J. Benzodiazepines: more "behavioral" addiction than dependence. Psychopharmacol. 2003;167(3):297-303. 
153. Lader M, Kyriacou A. Withdrawing benzodiazepines in patients with anxiety disorders. Curr Psychiatry Rep. 2016;18(1):8.

154. Petursson $\mathrm{H}$, Lader $\mathrm{MH}$. Withdrawal from long-term benzodiazepine treatment. Br Med J. 1981;283: 634-5.

155. Murphy SM, Owen RT, Tyrer PJ. Withdrawal symptoms after six week's treatment with diazepam. Lancet. 1984;2:1389.

156. Pétursson H. The benzodiazepine withdrawal syndrome. Addiction. 1994;89(11):1455-9.
157. LaCorte S. How chronic administration of benzodiazepines leads to unexplained chronic illnesses: a hypothesis. Med Hypotheses. 2018;118:59-67.

158. Holton A, Riley P, Tyrer P. Factors predicting longterm outcome after chronic benzodiazepine therapy. J Affect Disord. 1992;24(4):245-52. https://doi. org/10.1016/0165-0327(92)90109-j.

159. Wright S. Benzodiazepine withdrawal: clinical aspects. In: Peppin J, Raffa R, Pergolizzi J, Wright S, editors. The benzodiazepines crisis: an overview of the down-side of an overused drug class. New York: Oxford University Press; 2020. 